stage, and to ensure adequate attention to the subject an obligatory examination is the only certain method.

\title{
Test Types for the Illiterate
}

A committee, the members of which comprised Edward Jackson, N. M. Black, W. B. Lancaster, and A. E. Ewing, has presented its report upon the standardization of test types for the illiterate to the Section of Ophthalmology of the American Medical Association.

Over one hundred and eighty difterent figures were examined, and certain ones were selected, namely, the ring, square, star, pitcher, cross, horseshoe, flag, fork, and chair. The choice was based upon the following principles: (1) the lines of which the chief framework of the character is constructed should each subtend the angle of one minute. (2) The main body of the character should conform to the five minute visual angle. (3) Slight unobtrusive variations may be made in the lengths of the lines of the characters beyond the five minute angle, in order to insure legibility, as it is practically impossible to construct pictures of ordinary well known objects in the five minute space with lines of one minute thickness. (4) Masses of black are undesirable. (5) Finer lines than subtend the angle of one minute are to be avoided in the body of the character. (6) As any one character cannot be depended on for a visual measurement, the smaller characters for distances less than twenty metres should be arranged in rows of three or four each. The reading of the row at the correct distance is considered by the committee to be the equivalent of $\mathrm{V} .=1$.

The interval may be in any ratio, but the geometric ratios of Green are suggested as being most advisable. The figures should be printed in black upon a creamy white background on paper or board of a thickness adequate to prevent the type sinking into it. As the committee points out, there is a distinct advantage in having a relatively small number of characters repeated on successive lines of the chart, for in that way it can be known from the larger lines whether the person tested understands and responds properly to the test. The characters selected by the committee conform so well to the letter tests that the two may be readily interchanged. In addition to the characters now recommended by the committee, several "one minute" tests have been considered, such as the Snellen "E," the Landolt "Broken Ring," the Jackson "Incomplete Square," and the "Incomplete Parallelogram" forms of Pergens, besides the several varying one to three minute tests of Pergens, the "Crosspoint" and "Line-point" tests of Wolffberg, and the Central Broken Line test of Ewing. Taken singly each of the tests last named is practically the equivalent of the others. They are excellent when any question of a fine degree 
of visual acuity is involved, as well as for the repeated testing of those with greatly reduced vision. The difficulty concerns the amount of time consumed by their employment. For obtaining some idea of the vision of very young children the committee endorses the suggestion of Worth, namely, that balls of various sizes be employed. But in place of the ivory used by Worth, some noiseless material, such as paper, yarn, cork, or rubber, painted white or black to contrast with the background, would be preferable.

\section{Night-blindness}

The terms hemeralopia and nyctalopia to designate defective vision by night, are so liable to misinterpretation, that most writers in the English tongue have abandoned their use and write and speak of night-blindness. Our continental confrères, however, have generally adhered to the term hemeralopia, though often substituting the unequivocal French expression amblyopie crépusculaire.

Recognizing that the word hemeralopia, as used, is a mistranslation and has been employed on many occasions to indicate either of two visual defects, Terson (Arch. d'Ophtal., Jan.-Feb., 1919) proposes the introduction of a new term: Hesperanopia, which he thinks will not only avoid confusion, but is grammatically and clinically unobjectionable. This word, derived from $\check{\sigma} \sigma \pi \epsilon \rho o s$, dusk, and $\vec{a}$, privative, seems to offer an acceptable solution of the difficulty which has arisen from a term (hemeralopia) whose commonly accepted meaning is the exact opposite of that which its derivation implies. Terson's suggested adoption of the word Hesperanopia for the condition, and Hesperanope, for the subject of night-blindness, is deserving of encouragement.

\section{ABSTRACTS}

\section{I.-PITUITARY HEADACHES.}

\section{Pardee, Irving H. (New York).-Pituitary headaches and their cure. Arch. Internal Medicine, February i5, I9I9.}

The part which the pituitary gland may play in the causation of headache is frequently overlooked. One of the first manifestations of pituitary disease is a frontal headache which does not yield to the usual remedies. The headache of acromegaly is familiar to physicians, but Pardee describes headaches due to early affections of the hypophysis before there are any permanent structural changes 